\title{
Monitoring of lung malignant epithelial cells by gene methylation analysis in the conditionally reprogrammed cell cultures
}

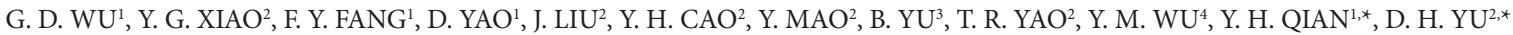 \\ ${ }^{1}$ Department of Thoracic Surgery, 2nd People's Hospital of Shenzhen, Shenzhen, China; ${ }^{2}$ USK Bioscience, Shenzhen, China; ${ }^{3}$ Feinberg School of \\ Medicine, Northwestern University, Chicago, USA; 4 Department of Histopathology, Xiaolan People's Hospital, Zhongshan, China
}

*Correspondence: 13602585160@163.com, derek.yu@uskbio.com

Received July 30, 2019 / Accepted October 16, 2019

\begin{abstract}
Conditionally reprogrammed cell (CRC) technology is an effective method for culturing primary malignant cells and non-malignant epithelial cells in vitro. This can be useful for precision medicine applications, such as drug sensitivity assays. However, this approach is commonly hindered by the non-specific growth of non-malignant epithelial cells in CRC cultures and the lack of effective biomarkers/assays to distinguish them from primary tumor cells. In this study, we developed a DNA methylation-based, real-time PCR assay to investigate SHOX2 and PTGER4 gene promoters as sensitive markers for human lung cancer. We first found that in formalin-fixed, paraffin-embedded (FFPE) malignant lung samples, 90\% (28/31) had increased SHOX2 and/or PTGER4 promoter methylation as compared with their adjacent non-malignant samples. We then applied this assay to fresh surgical tumors and found increased SHOX2 and/or PTGER4 promoter methylation in $80 \%$ $(20 / 25)$ of tumor samples as compared with their corresponding adjacent non-malignant tissues. Increased methylation of SHOX2 or PTGER4 promoter regions was also detected in 52\% (13/25) of CRC cultures. The presence of malignant cells was confirmed by growth in soft agar cultures, a hallmark of malignant transformation, as well by EGFR mutation analysis. These results demonstrate that SHOX2 and PTGER4 promoter methylation levels can be used to detect malignant lung epithelial cells in CRC cultures.
\end{abstract}

Key words: SHOX2, PTGER4, gene methylation, CRCs, soft agar, EGFR

Lung cancer is the leading cause of cancer mortality worldwide [1]. Although the overall prognosis for lung cancer has improved since the application of targeted therapies and checkpoint immune therapies, there is still a strong clinical need for systemic chemotherapy due to evolving tumor heterogeneity [2]. Because ineffective therapies can lead to patient harm, loss of treatment opportunities and a waste of medical resources, the approaches to predict and improve clinical efficacy are urgently needed.

One of these approaches is in vitro cell culturing of primary tumors that can be applied as drug sensitivity assays to guide chemotherapy selection. Despite many efforts to optimize this approach, very little success has been achieved in the clinical setting for a number of reasons [3]. First, the success rate for the conversion of a primary tumor to the cell culture is very low, ranging from $10 \%$ to $40 \%$ [3]. In addition, successful in vitro inoculations can take 6-8 weeks, or even longer, to obtain sufficient cell numbers for drug sensitivity testing [4]. This is much longer than the therapeutic window (generally 2-3 weeks) between surgery and initiation of adjuvant treatment. The concordance between traditional
2D in vitro drug sensitivity assays and actual clinical efficacy is also low, ranging from $46-80 \%$, possibly due to different cellular structures and microenvironments between in vivo tumors and in vitro cultures [4].

The recent development of conditionally reprogrammed cells (CRCs), has significantly improved success rates of cell cultures of primary tumors $[5,6]$. Tumor cells in CRC cultures are "immortalized" and maintain the characteristics of the original tumors, which better facilitate in vitro drug sensitivity assays [5]. Indeed, several groups have reported using CRC cultures to guide personalized therapy, including lung cancer [5,7-11]. However, the preferential proliferation of non-malignant epithelial cells over the malignant cells from primary tumors in CRC cultures hinders the establishment of reliable malignant cell models [12]. The lack of effective biomarkers and assays to distinguish malignant from non-malignant epithelial cells in CRC cultures also impedes the selective cultivation of malignant cells.

One promising solution relies on DNA methylation patterns, which play an important role in regulating cellular differentiation and development [13]. Aberrant methyla- 
tion comprises a major epigenetic feature of human cancers, including lung cancer $[14,15]$. Previous studies showed that increased SHOX2 and PTGER4 promoter methylation was detected in lung cancer tissues when compared with matched, non-malignant tissues $[16,17]$. In this study, we established a sensitive and specific, PCR-based, DNA methylation assay examining SHOX2 and PTGER4 gene promoters to detect malignant epithelial cells in CRC cultures.

\section{Patients and methods}

Tissue collection and processing. Malignant and non-malignant FFPE lung samples were collected from pathology laboratories of Xiaolan People's Hospital of Zhongshan under the regulations of its ethics board and routing diagnostic. 2-3 pieces of paraffin slice prepared from FFPE blocks were used for DNA extraction.

All fresh cancer tissue specimens were collected from curative intent surgeries at Shenzhen Second People's Hospital under the regulations of its ethics board. Both malignant and adjacent non-malignant lung tissue samples were collected from patients to allow for matching. Resident pathologists inspected and classified all resected lung carcinomas by histopathology - tumor tissues were defined as less than $15 \%$ normal cells. The tumor and non-cancerous tissues were transported to the laboratory in ice-cold sterile transport medium. Tissues were washed extensively in Hank's balanced salt solution containing penicillin, streptomycin, and amphotericin B (Gibco, Thermo Fisher Scientific), then minced into 1-2 mm small fragments. Tissues were digested with dispase II and collagenase I (Sigma, St. Louis, MO, USA) at $37^{\circ} \mathrm{C}$ for $2 \mathrm{~h}$ to obtain cell suspensions.

Cell culture. Swiss-3T3-J2 mouse fibroblast and A549 cells were obtained from the American Type Culture Collection (ATCC, USA) and cultured in Dulbecco's Modified Eagle Medium (DMEM) (Gibco, Thermo Fisher Scientific) supplemented with 10\% FBS (Gibco, Thermo Fisher Scientific, Australia) and 1\% (v/v) penicillin/streptomycin. All cells used in the culture were tested for and found to be mycoplasma-free. Swiss-3T3-J2 mouse fibroblasts (J2 feeder cells) were irradiated at $30 \mathrm{~Gy}$ as described previously [7]. For CRC cultures, epithelial cells from tumor samples and their adjacent tissues were co-cultivated with irradiated (30 Gy) J2 feeder cells culture in F medium consisting of 3:1 (v/v) F-12 Nutrient Mixture (Ham) - DMEM, 5\% (v/v) FBS, $1 \%(\mathrm{v} / \mathrm{v})$ penicillin/streptomycin, $0.4 \mu \mathrm{g} / \mathrm{ml}$ hydrocortisone, $5 \mu \mathrm{g} / \mathrm{ml}$ insulin, $8.4 \mathrm{ng} / \mathrm{ml}$ cholera toxin, $10 \mathrm{ng} / \mathrm{ml}$ epidermal growth factor, and $24 \mu \mathrm{g} / \mathrm{ml}$ adenine (all Sigma-Aldrich) with addition of $5 \mu \mathrm{M}$ Y-27632 (ROCK inhibitor, Enzo Life Sciences) [9].

Methylation specific PCR assay. DNA samples were extracted from FFPE slides, fresh tumor tissues, matched non-malignant tissues and cell cultures by utilizing the QIAamp DNA Mini Kit (50) (Qiagen, Hilden, Germany) according to the recommended protocol [18]. The DNA samples were then subjected to bisulfite modification using the EpiTect Fast DNA Bisulfite Kit (200) (Qiagen, Hilden, Germany) according to the protocol. The methylation PCR assay for detecting methylated SHOX2 and PTGER4 genes has been described previously $[19,20]$. Real-time PCR (Taqman probe assay) was performed using an ABI 7500 Fast Real-Time PCR System (Applied Biosystems, CA, USA) using the following temperature profile: $2 \mathrm{~min} / 95^{\circ} \mathrm{C}$ and 50 cycles with $15 \mathrm{~s} / 95^{\circ} \mathrm{C}$ and $30 \mathrm{~s} / 59^{\circ} \mathrm{C}$. The probes and primers for SHOX2, PTGER4, and ACTB (Table 1) were optimized according to the previous publication [21]. $1 \mathrm{ng}$ bisulfite transformed DNA template and $0.2 \mu \mathrm{M}$ probe were added to $50 \mu \mathrm{l}$ reaction. Bisulfite transformed DNA purified from A549 and human lung fibroblast cell lines were used as positive and negative controls, respectively. For each sample, a relative methylation value was determined using the $\Delta \Delta \mathrm{CT}$ method adapted for DNA methylation analyses as previously described [21]. The percentage of methylated sites was calculated using the following formula: Methylation Sample $=100 \%{ }^{\star} 2^{\Delta \Delta \mathrm{CT}}$ Sample [22].

EGFR mutation analysis. EGFR mutations were analyzed with the amplification refractory mutation system (ARMS)based EGFR mutation detection technology as described previously [23-27]. Primers and probes for mutation analysis were synthesized by Invitrogen (Thermo Fisher Scientific, China). Genomic DNA was isolated from non-cancerous tissues, tumor tissues and CRCs using the Qiagen Genomic DNA Extraction Kit (Qiagen, Hilden, Germany) [10]. After DNA extraction, samples were subjected to the ARMS-based PCR assay, which detects 31 specific EGFR gene mutations by real-time polymerase chain reaction (RT-PCR). This includes 19 distinguished deletions in exon 19, L858R, L861Q, G719X (X = C, S, A), S768I, T790M, C797S, T790M-C797S, and three insertions in exon 20. RT-PCR assays were carried out on an ABI 7500 PCR machine according to the manufactur-

Table 1. Oligonucleotide specifications.

\begin{tabular}{|c|c|}
\hline Oligonucleotide & Sequence $5^{\prime} \rightarrow 3^{\prime}$ \\
\hline \multicolumn{2}{|l|}{ SHOX2 } \\
\hline Forward Primer & GTTTTTTGGATAGTTAGGTAAT \\
\hline Reverse Primer & TAACCCGACTTAAACGACGA \\
\hline Forward Blocker & $\begin{array}{l}\text { TAATTTTTGTTTTGTTTGTTTGATTGGGGTTG- } \\
\text { TATGA-SpacerC3 }\end{array}$ \\
\hline Hydrolysis Probe & FAM-CTCGTACGACCCCGATCG-BHQ1 \\
\hline \multicolumn{2}{|l|}{ PTGER4 } \\
\hline Forward Primer & GGTAAGGTTGGGGAGGTAG \\
\hline Reverse Primer & AAACACCGAACAACACCAC \\
\hline Reverse Blocker & ACCTCAACAACTTTCAACACCACCA-Spacer C3 \\
\hline Hydrolysis Probe & CY5-ACCGCGACCGCCTCGATTA-BHQ1 \\
\hline \multicolumn{2}{|l|}{ ACTB } \\
\hline Forward Primer & GTGATGGAGGAGGTTTAGTAAGTT \\
\hline Reverse Primer & ССААТАAААССТАСТССТСССТТАА \\
\hline Hydrolysis Probe & $\begin{array}{l}\text { JOE-ACCACCACCCAACACACAATAACAAACA- } \\
\text { CA-BHQ1 }\end{array}$ \\
\hline
\end{tabular}


er's protocol. Data analyses were performed using the 7500 software v2.3.

Soft agarose assay. Soft agar cultures of cells for anchorage-independent growth in 96-well plates were performed as previously described [28]. A mixture of $25 \mu$ l pre-warmed $\left(37^{\circ} \mathrm{C}\right)$ F-medium containing $10 \% \mathrm{FBS}$, $4 \mathrm{mM}$ Glu, $100 \mathrm{U} / \mathrm{ml}$ penicillin/streptomycin, and $25 \mu \mathrm{l}$ pre-warmed $\left(56^{\circ} \mathrm{C}\right) 1.2 \%$ soft agar was plated onto each well of a 96 -well microplate to serve as a pre-layer for the assay. $50 \mu \mathrm{l}$ of $0.4 \%$ agarose containing $1 \times 10^{3}$ cells was layered over the solidified pre-layer. Finally, $50 \mu \mathrm{l}$ of F-medium was added on top of the solidified cell layers to prevent desiccation. The cells were cultured in a humidified $37^{\circ} \mathrm{C}$ incubator with $5 \%$ $\mathrm{CO}_{2}$ for 1-2 weeks, and then cell proliferation and viability were scored using the Alamar Blue assay. Cell growth was measured using a Fluoroskan FL Reader, with excitation at $530 \mathrm{~nm}$ and emission at $590 \mathrm{~nm}$.

Statistics. Statistical analysis and data normalization were conducted in repeated experiments. The receiver operating characteristic (ROC) and the area under the ROC curve (AUC) were constructed using IBM SPSS statistics 19. The test variable was the percentage of methylation and state variable were 0 and 1 , in which 1 represents tumor tissues and 0 represents non-malignant tissues in ROC curve analysis. The cut-off was chosen to reduce the false positive rate to less than $5 \%$ for non-malignant samples. Data were analyzed and plotted in GraphPad Prism 5.

\section{Results}

Increased SHOX2 and PTGER4 promoter methylation in malignant lung tumors. Previous studies showed that increased levels of SHOX2 and PTGER4 promoter methylation were observed in non-small cell lung cancer (NSCLC). Using our DNA methylation RT-PCR assay to analyze 31 matched FFPE samples, we found increased SHOX2 and PTGER4 promoter methylation in tumor tissues as compared to their non-cancerous adjacent tissues (Figure 1). Using a cut-off of $8.9 \%$ SHOX2 methylation, we obtained a sensitivity of $78 \%$ in malignant samples with an area under the curve (AUC) of 0.87 . Using the same cut-off of $8.9 \%$ for PTGER4 methylation, we obtained a sensitivity of $84 \%$ and a specificity of $97 \%$. PTGER4 methylation thus demonstrated significant discriminatory power $(\mathrm{AUC}=0.91)$. Combined the SHOX2 and PTGER4 methylation can increase the sensitivity to $90 \%$ with a specificity of $90 \%$ (AUC $=0.96$, Supplementary Figure S1). Our results confirmed that the DNA methylation levels of SHOX2 and PTGER4 were selectively upregulated in lung cancer tissues, suggesting its potential for distinguishing tumor cells and non-cancerous cells.
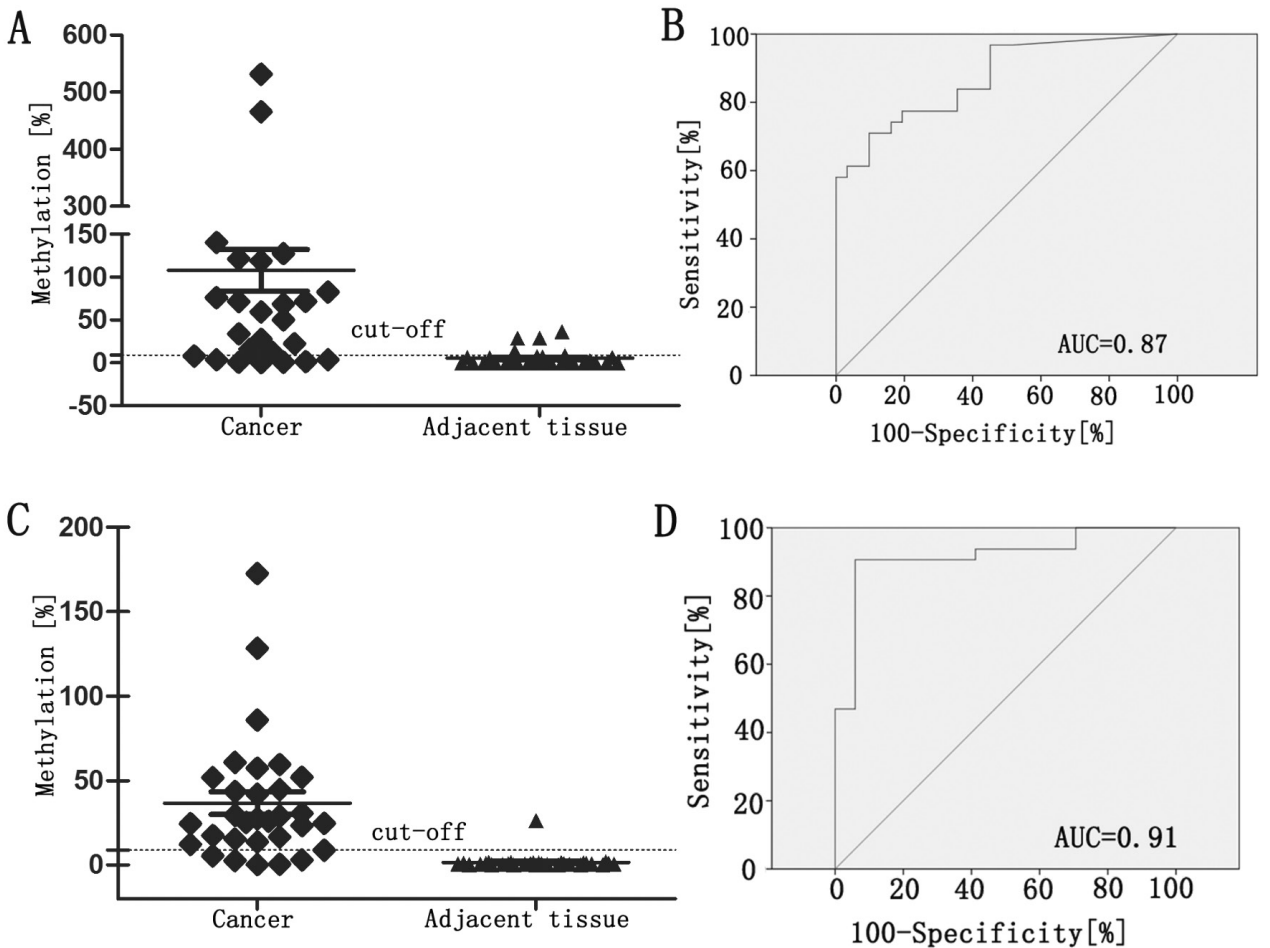

Figure 1. Validation of the SHOX2 and PTGER4 DNA methylation expression in lung tumor tissues. DNA was isolated from 31 matched FFPE patients' samples (cancer and non-cancerous) and subjected to methylation specific PCR analysis. A) SHOX2 methylation level measured in cancer and adjacent tissues when using optimal cut-off $8.9 \%$ for samples analysis. B) ROC and the resulting AUC analysis of SHOX2 study (AUC=0.87). C) PTGER4 methylation level measured in tumors and adjacent samples. D) ROC and AUC analysis of PTGER4 study (AUC=0.91). 
Next, we measured SHOX2 and PTGER4 promoter methylation levels in 25 fresh surgical lung tumors and their adjacent non-malignant samples, as well as in their corresponding in vitro CRC cultures. The characteristics of these patients who contributed fresh tissues are described in Table 2, which includes information on histological type and disease stage. The mean age of our patients was approximately 60 years. The majority of these specimens were adenocarcinomas and early stage tumors.

When the same $8.9 \%$ methylation was used as a cut-off, increased methylation of SHOX2 and PTGER4 promoters was detected in $80 \%$ of tumor samples (20/25) (Figure $2 \mathrm{~A}$ ). Using the same cut-off value, increased SHOX2 and PTGER4 promoter methylation were detected in 52\% (13/25) of CRC cultures, while it was undetectable in all CRC cultures from the matched non-malignant tissues (0/25) (Figures 2C, 2D). These results demonstrate a discriminatory utility in assaying SHOX2 and PTGER4 promoter methylation to detect malignant cells in CRC cultures.
Correlation between SHOX2 and PTGER4 promoter methylation and anchorage-independent CRC growth. Our previous results demonstrate that the detection of increased SHOX2 and PTGER4 promoter methylation correlates with tumor presence in CRC cultures. Because only transformed cells are able to grow in soft agar cultures, we further tested the growth property of these CRC cultures in soft agar cultures. Among 13 CRC cultures with high levels of SHOX2 and PTGER4 promoter methylation, 8 of them could proliferate in soft agar and form colonies (Figure 3, Table 3). Most of the CRC cells with low levels of SHOX2 and PTGER4 promoter methylation, including those from non-malignant tissues, were not able to proliferate or form colonies in agarose. Together, our results demonstrate that SHOX2 and PTGER4 promoter methylation can be used to discriminate tumor cells in CRC cultures and guide in vitro functional assays.

Maintenance of EGFR mutations in the CRC cultures. To verify that our CRC cultures continued to grow tumor
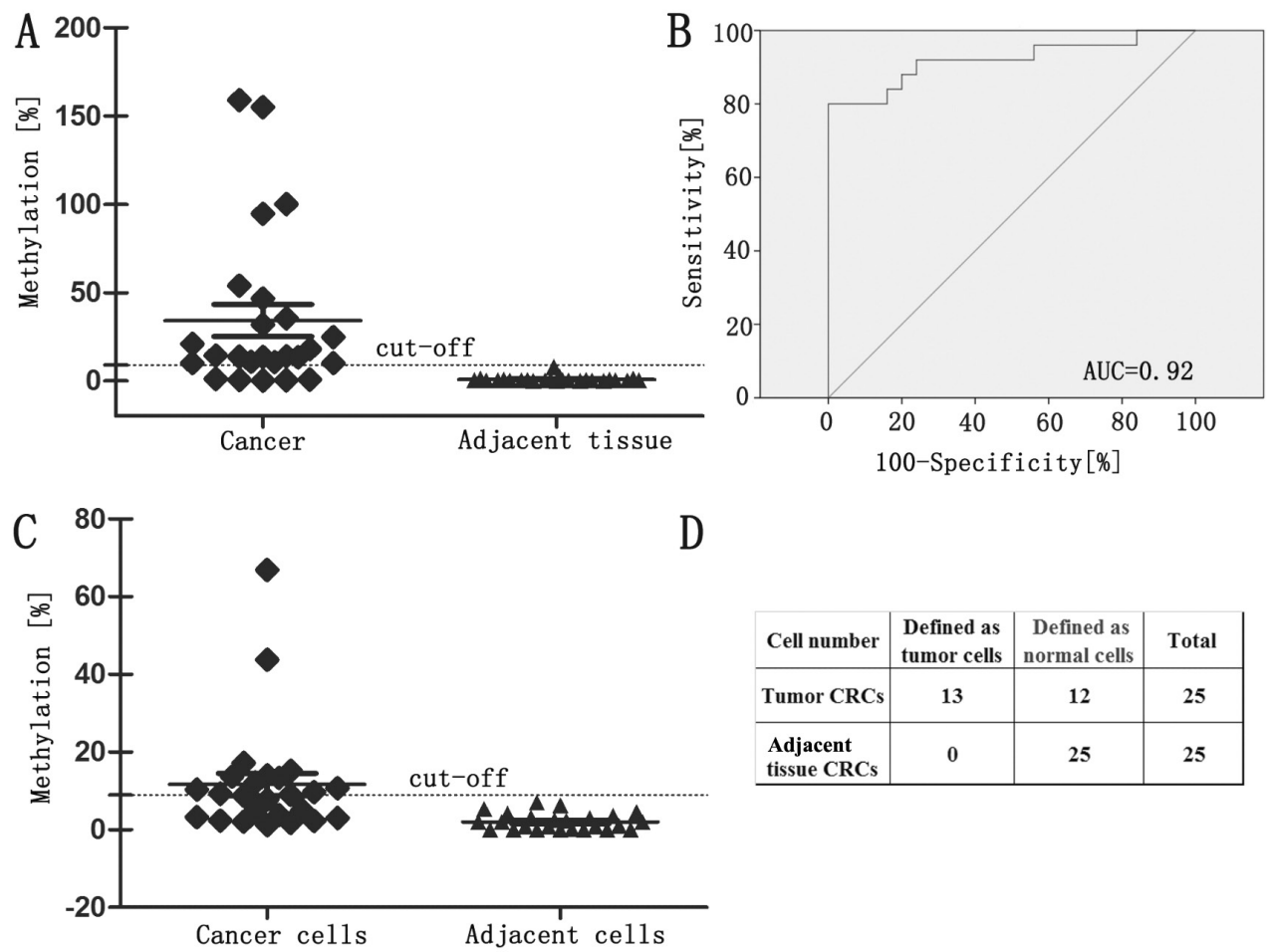

D

\begin{tabular}{|l|c|c|c|}
\hline Cell number & $\begin{array}{c}\text { Defined as } \\
\text { tumor cells }\end{array}$ & $\begin{array}{c}\text { Defined as } \\
\text { normal cells }\end{array}$ & Total \\
\hline Tumor CRCs & 13 & 12 & 25 \\
\hline $\begin{array}{c}\text { Adjacent } \\
\text { tissue CRCs }\end{array}$ & 0 & 25 & 25 \\
\hline
\end{tabular}

Figure 2. Maintenance of DNA methylation of SHOX2 and PTGER4 genes in lung cancer CRC cultures. DNA was isolated from 25 paired fresh tissue samples (cancer and non-cancerous) and their CRC cultures, and subjected to methylation specific PCR analysis. A) The methylation levels of SHOX2 and PTGER4 measured in fresh cancer and adjacent tissues. B) ROC and the resulting AUC analysis of SHOX2 and PTGER4. C) SHOX2 and PTGER4 methylation levels measured in CRCs from tumors and adjacent samples. D) Summary of the methylation status of SHOX2 and PTGER4 gene in CRC cultures.

Table 2. Clinical information of the patients with lung cancer.

\begin{tabular}{|c|c|c|c|c|c|c|c|c|c|}
\hline Number of patients & Average age (range) & Female/Male & & Histological Subtype & & & Tur & ta & \\
\hline & & & Adenocarcinoma & Squamous cell carcinoma & Other type & I & II & II & IV \\
\hline 25 & $60.36(36-80)$ & $13 / 12$ & 22 & 2 & 1 & 12 & 7 & 6 & 0 \\
\hline
\end{tabular}


A

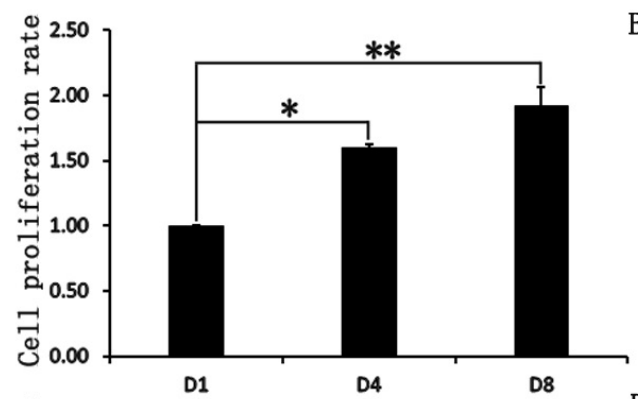

C

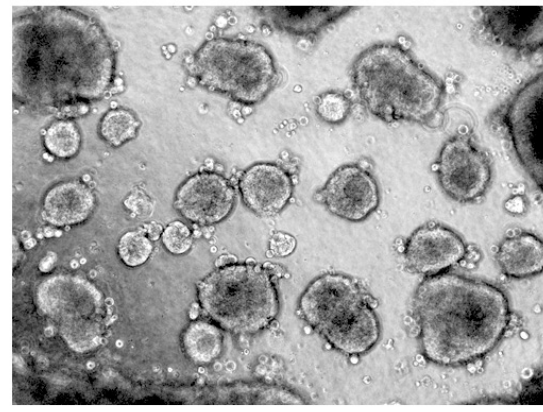

E

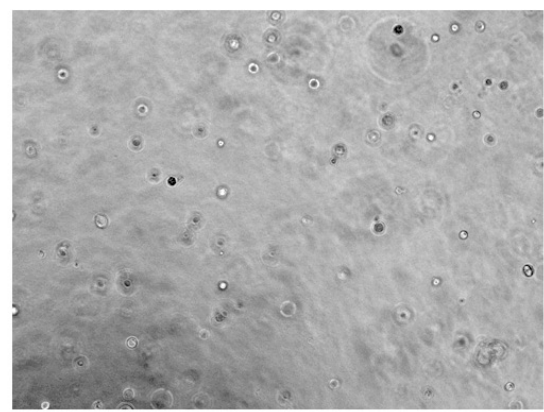

B

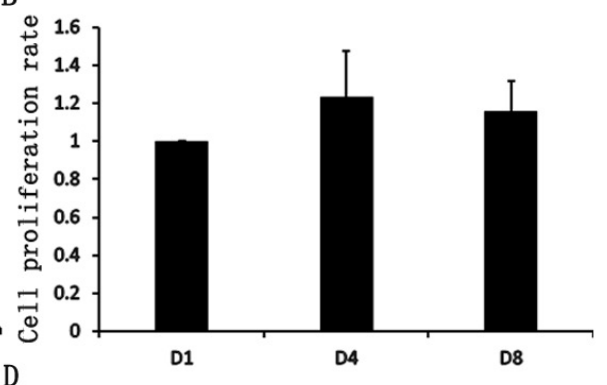

D
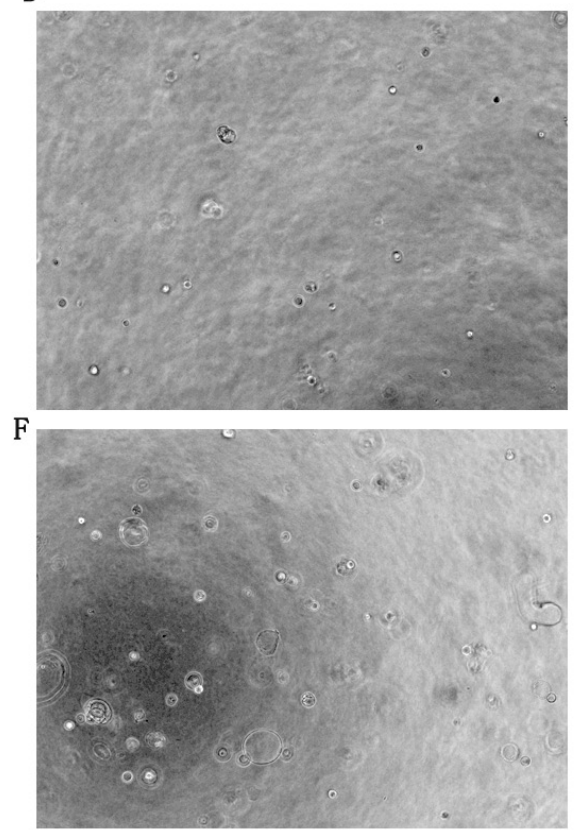

Figure 3. Growth properties of CRCs in soft agar cultures. The average proliferation rate of 13 tumor cell cultures with high methylation levels on day 1, day 4, and day 8 (A) and 12 tumor cell cultures with low methylation levels on day 1, day 4, and day 8 (B) in agarose culture was determined. Data were generated from three independent experiments ${ }^{\star} p<0.05 ;{ }^{*} p<0.01$, Student's $t$ test, $n=3$. Error bars depict mean $\pm S$.E. Tumor cells with high methylation of SHOX2 and PTGER4 (C) and the corresponding adjacent tissues (D) and tumors with low methylation of SHOX2 and PTGER4 (E) and the corresponding adjacent tissues $(\mathrm{F})$ were plated in $0.4 \%$ agarose with conditioned F-media and overlaid on $0.6 \%$ agar.

cells from the primary lung cancers, we used an ARMS-based assay to test for mutations in EGFR, the most frequently mutated driver gene in lung cancer. This was performed on our 25 fresh tumor tissues and their corresponding $2^{\text {nd }}$ generation of CRC cultures. EGFR mutations were detected in 56\% $(14 / 25)$ of the tissue samples, of these, EGFR mutations were sustained in 50\% (7/14) CRC cultures, indicating the maintenance of lung cancer cells in a portion of the CRC cultures (Table 4).

\section{Discussion}

Since being initially reported in 2014, the success rate of CRC-based in vitro cultures for numerous types of primary malignant and non-malignant cells has increased significantly [7]. Recently, however, Gao et al. reported that non-malig- nant lung epithelial cells over-proliferated in CRC cultures from resected NSCLC specimens [12]. Due to the lack of feasible biomarkers, they had to identify malignant epithelial cells in CRC cultures by more intensive approaches. These included next generation sequencing (NGS) for mutation and copy number variation (CNV) analysis, and microarray assays of the whole transcriptome mRNA expression. These approaches, however, are not practical in clinical or routine laboratory settings.

In the present study, we aimed to develop a more feasible assay for distinguishing tumor from normal epithelial cells to assist further optimization of CRC culture conditions. Our results demonstrated that SHOX2 and PTGER4 promoter methylations have an average sensitivity of $85 \%$ and an average specificity of $95 \%$ for detecting malignant lung epithelial cells, which is consistent with previous studies 
Table 3. Correlation between hypermethylation and cell growth in soft agar.

\begin{tabular}{|c|c|c|}
\hline Cell number & Soft agar grow & Hypermethylated cells \\
\hline Sample 1 & + & + \\
\hline Sample 2 & + & + \\
\hline Sample 3 & - & - \\
\hline Sample 4 & + & + \\
\hline Sample 5 & + & + \\
\hline Sample 6 & - & + \\
\hline Sample 7 & - & + \\
\hline Sample 8 & - & - \\
\hline Sample 9 & + & + \\
\hline Sample 10 & + & + \\
\hline Sample 11 & - & + \\
\hline Sample 12 & - & - \\
\hline Sample 13 & - & - \\
\hline Sample 14 & - & - \\
\hline Sample 15 & - & + \\
\hline Sample 16 & + & + \\
\hline Sample 17 & - & - \\
\hline Sample 18 & - & + \\
\hline Sample 19 & - & - \\
\hline Sample 20 & - & - \\
\hline Sample 21 & - & - \\
\hline Sample 22 & - & - \\
\hline Sample 23 & + & - \\
\hline Sample 24 & + & + \\
\hline Sample 25 & + & - \\
\hline Total numbers & 10 & 13 \\
\hline
\end{tabular}

[20]. Using this DNA methylation assay, we also observed cells with detectable methylation of SHOX2 and PTGER4 promoters in CRC cultures from lung cancer tissues, which were further confirmed as malignant by anchorage-independent soft agar growth (a hallmark of transformed cells) and EGFR mutation analysis [29].

Although a positive correlation between cells with methylation status and proliferation in soft agar culture was observed, we found that 5 out of 13 CRC cultures, testing positive for increased SHOX2 and PTGER4 promoter methylation, could not proliferate in soft agar culture. These phenomena were consistent with previous observations that not all cancer cell lines can grow in soft agar [29-31]. On the other hand, CRC cultures negative for SHOX2 and PTGER4 methylation could grow in soft agar, indicating that SHOX2 and PTGER4 methylation is not an exclusive biomarker for all lung cancer cases.

Compared with Gao et al. [12], we observed more malignant cells in CRC cultures. This could be due to the differences in sample processing, such as tissue storage and digestion conditions. Overall, we also observed a reduced population of malignant lung cancer cells in CRC cultures,
Table 4. EGFR mutations detected in tumor tissues and CRC cultures.

\begin{tabular}{|c|c|c|c|}
\hline Sample & Mutation site & Tumor tissues & CRCs \\
\hline Sample 1 & - & - & - \\
\hline Sample 2 & - & - & - \\
\hline Sample 3 & L861Q & + & - \\
\hline Sample 4 & 19del & + & - \\
\hline Sample 5 & L858R & + & + \\
\hline Sample 6 & - & - & - \\
\hline Sample 7 & - & - & - \\
\hline Sample 8 & - & - & - \\
\hline Sample 9 & - & - & - \\
\hline Sample 10 & L858R & + & + \\
\hline Sample 11 & - & - & - \\
\hline Sample 12 & - & - & - \\
\hline Sample 13 & - & - & - \\
\hline Sample 14 & 19del & + & - \\
\hline Sample 15 & L861Q & + & - \\
\hline Sample 16 & L858R & + & + \\
\hline Sample 17 & $719 \mathrm{X}$ & + & + \\
\hline Sample 18 & - & - & - \\
\hline Sample 19 & - & - & - \\
\hline Sample 20 & $719 \mathrm{X}$ & + & - \\
\hline Sample 21 & L858R/L861Q/719X & + & - \\
\hline Sample 22 & $719 \mathrm{X}$ & + & + \\
\hline Sample 23 & L858R & + & + \\
\hline Sample 24 & L858R & + & + \\
\hline Sample 25 & L861Q & + & - \\
\hline Total & & 14 & 7 \\
\hline
\end{tabular}

measured by either loss of or reduced SHOX2 and PTGER4 promoter methylation, as compared with their precedent tissues. This suggests that non-malignant lung cancer cells over-grow malignant cells in CRC cultures, which is consistent with Gao's observation.

The application of SHOX2 and PTGER4 promoter methylation assays to monitor malignant lung cancer cells in CRC cultures can facilitate the optimization of culture conditions for primary cancer cells. This could broaden the utility of CRC cultures to finally be applied in a clinically meaningful way, such as for in vitro drug sensitivity assays and new drug development [4]. Moving forward, we hope that the validity of this approach can be expanded to other types of cancers and their respective biomarkers to improve the treatment and management of potentially devastating cancers.

Supplementary information is available in the online version of the paper.

Acknowledgments: This work was supported by the Shenzhen Science and Technology Innovation Committee (grant number 20170329181141615). 


\section{References}

[1] WORLD HEALTH ORGANIZATION 2015 https://www. who.int/news-room/fact-sheets/detail/cancer 2015

[2] MOHAMMAD RM, MUQBIL I, LOWE L, YEDJOU C, HSU HY et al. Broad targeting of resistance to apoptosis in cancer. Semin Cancer Biol 2015; 35: S78-S103. https://doi. org/10.1016/j.semcancer.2015.03.001

[3] ASPINALL MG, HAMERMESH RG. Realizing the promise of personalized medicine. Harv Bus Rev 2007; 85: 108-117, 165.

[4] HALFTER K, DiTSCH N, KOLBERG HC, FISCHER H, HAUZENBERGER T et al. Prospective cohort study using the breast cancer spheroid model as a predictor for response to neoadjuvant therapy--the SpheroNEO study. BMC Cancer 2015; 15: 519. https://doi.org/10.1186/s12885-0151491-7

[5] SUPRYNOWICZ FA, UPADHYAY G, KRAWCZYK E, KRAMER SC, HEBERT JD et al. Conditionally reprogrammed cells represent a stem-like state of adult epithelial cells. Proc Natl Acad Sci U S A 2012; 109: 20035-20040. https://doi.org/10.1073/pnas.1213241109

[6] AGARWAL S, RIMM DL. Making every cell like HeLa a giant step for cell culture. Am J Pathol 2012; 180: 443-445. https://doi.org/10.1016/j.ajpath.2011.12.001.

[7] YUAN H, MYERS S, WANG J, ZHOU D, WOO JA et al. Use of reprogrammed cells to identify therapy for respiratory papillomatosis. N Engl J Med 2012; 367: 1220-1227. https:// doi.org/10.1056/NEJMoa1203055

[8] SAENZ FR, ORY V, ALOTAIBY M, ROSENFIELD S, FURLONG $\mathrm{M}$ et al. Conditionally reprogrammed normal and transformed mouse mammary epithelial cells display a progenitor-cell-like phenotype. PLoS One 2014; 9: e97666. https://doi.org/10.1371/journal.pone.0097666

[9] Liu X, Ory V, Chapman S, Yuan H, Albanese C et al. ROCK inhibitor and feeder cells induce the conditional reprogramming of epithelial cells. Am J Pathol 2012; 180: 599-607. https://doi.org/10.1016/j.ajpath.2011.10.036

[10] SAEED K, RAHKAMA V, ELDFORS S, BYCHKOV D, MPINDI JP et al. Comprehensive Drug Testing of Patientderived Conditionally Reprogrammed Cells from Castration-resistant Prostate Cancer. Eur Urol 2017; 71: 319-327. https://doi.org/10.1016/j.eururo.2016.04.019

[11] CRYSTAL AS, SHAW AT, SEQUIST LV, FRIBOULET L, NIEDERST MJ et al. Patient-derived models of acquired resistance can identify effective drug combinations for cancer. Science 2014; 346: 1480-1486. https://doi.org/10.1126/science. 1254721

[12] GAO B, HUANG C, KERNSTINE K, PELEKANOU V, KLUGER $Y$ et al. Non-malignant respiratory epithelial cells preferentially proliferate from resected non-small cell lung cancer specimens cultured under conditionally reprogrammed conditions. Oncotarget 2017; 8: 11114-11126. https://doi.org/10.18632/oncotarget.14366

[13] CALLINAN PA, FEINBERG AP. The emerging science of epigenomics. Hum Mol Genet 2006; 15: R95-101. https:// doi.org/10.1093/hmg/ddl095
[14] BELINSKY SA. Gene-promoter hypermethylation as a biomarker in lung cancer. Nat Rev Cancer 2004; 4: 707-717. https://doi.org/10.1038/nrc1432

[15] DIETRICH D, KNEIP C, RAJI O, LILOGLOU T, SEEGEBARTH A et al. Performance evaluation of the DNA methylation biomarker SHOX2 for the aid in diagnosis of lung cancer based on the analysis of bronchial aspirates. Int J Oncol 2012; 40: 825-832. https://doi.org/10.3892/ijo.2011.1264

[16] ILSE P, BIESTERFELD S, POMJANSKI N, WROBEL C, SCHRAMM M. Analysis of SHOX2 methylation as an aid to cytology in lung cancer diagnosis. Cancer Genomics Proteomics 2014; 11: 251-258.

[17] ILSE P, BIESTERFELD S, POMJANSKI N, FINK C, SCHRAMM M. SHOX2 DNA methylation is a tumour marker in pleural effusions. Cancer Genomics Proteomics 2013; 10: 217-223.

[18] SCHRAMM M, WROBEL C, BORN I, KAZIMIREK M, POMJANSKI $\mathrm{N}$ et al. Equivocal cytology in lung cancer diagnosis: improvement of diagnostic accuracy using adjuvant multicolor FISH, DNA-image cytometry, and quantitative promoter hypermethylation analysis. Cancer Cytopathol 2011; 119: 177-192. https://doi.org/10.1002/cncy.20142

[19] SCHMIDT B, LIEBENBERG V, DIETRICH D, SCHLEGEL T, KNEIP C et al. SHOX2 DNA methylation is a biomarker for the diagnosis of lung cancer based on bronchial aspirates. BMC Cancer 2010; 10: 600. https://doi.org/10.1186/14712407-10-600

[20] WEISS G, SCHLEGEL A, KOTTWITZ D, KONIG T, TETZNER R. Validation of the SHOX2/PTGER4 DNA Methylation Marker Panel for Plasma-Based Discrimination between Patients with Malignant and Nonmalignant Lung Disease. J Thorac Oncol 2017; 12: 77-84. https://doi. org/10.1016/j.jtho.2016.08.123

[21] DIETRICH D, JUNG M, PUETZER S, LEISSE A, HOLMES EE et al. Diagnostic and prognostic value of SHOX2 and SEPT9 DNA methylation and cytology in benign, paramalignant and malignant pleural effusions. PLoS One 2013; 8: e84225. https://doi.org/10.1371/journal.pone.0084225

[22] DIETRICH D, HASINGER O, LIEBENBERG V, FIELD JK, KRISTIANSEN G et al. DNA methylation of the homeobox genes PITX2 and SHOX2 predicts outcome in non-smallcell lung cancer patients. Diagn Mol Pathol 2012; 21: 93-104. https://doi.org/10.1097/PDM.0b013e318240503b

[23] LUND-IVERSEN M, KLEINBERG L, FJELLBIRKELAND L, HELLAND A, BRUSTUGUN OT. Clinicopathological characteristics of 11 NSCLC patients with EGFR-exon 20 mutations. J Thorac Oncol 2012; 7: 1471-1473. https://doi. org/10.1097/JTO.0b013e3182614a9d

[24] ARCILA ME, NAFA K, CHAFT JE, REKHTMAN N, LAU $\mathrm{C}$ et al. EGFR exon 20 insertion mutations in lung adenocarcinomas: prevalence, molecular heterogeneity, and clinicopathologic characteristics. Mol Cancer Ther 2013; 12: 220-229. https://doi.org/10.1158/1535-7163.MCT-12-0620

[25] YASUDA H, KOBAYASHI S, COSTA DB. EGFR exon 20 insertion mutations in non-small-cell lung cancer: preclinical data and clinical implications. Lancet Oncol 2012; 13: e23-31. https://doi.org/10.1016/S1470-2045(11)70129-2 
[26] Oxnard GR, Lo PC, Nishino M, Dahlberg SE, Lindeman NI et al. Natural history and molecular characteristics of lung cancers harboring EGFR exon 20 insertions. J Thorac Oncol 2013; 8: 179-184. https://doi.org/10.1097/ JTO.0b013e $3182779 \mathrm{~d} 18$

[27] YASUDA H, PARK E, YUN CH, SNG NJ, LUCENA-ARAUJO AR et al. Structural, biochemical, and clinical characterization of epidermal growth factor receptor (EGFR) exon 20 insertion mutations in lung cancer. Sci Transl Med 2013; 5: 216ra177. https://doi.org/10.1126/scitranslmed.3007205

[28] KE N, ALBERS A, CLAASSEN G, YU DH, CHATTERTON JE et al. One-week 96-well soft agar growth assay for cancer target validation. Biotechniques 2004; 36: 826-828, 830, 832-833. https://doi.org/10.2144/04365ST07
[29] TANG Z, MA H, MAO Y, AI S, ZHANG P et al. Identification of stemness in primary retinoblastoma cells by analysis of stem-cell phenotypes and tumorigenicity with culture and xenograft models. Exp Cell Res 2019; 379: 110-118. https:// doi.org/10.1016/j.yexcr.2019.03.034

[30] CAO Y, E G, WANG E, PAL K, DUTTA SK et al. VEGF exerts an angiogenesis-independent function in cancer cells to promote their malignant progression. Cancer Res 2012; 72: 3912-3918. https://doi.org/10.1158/0008-5472.CAN-114058

[31] SINGH SK, CLARKE ID, TERASAKI M, BONN VE, HAWKINS C et al. Identification of a cancer stem cell in human brain tumors. Cancer Res 2003; 63: 5821-5828. 


\section{Monitoring of lung malignant epithelial cells by gene methylation analysis in the conditionally reprogrammed cell cultures}

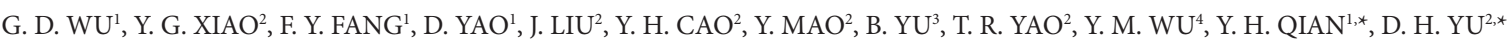

Supplementary Information
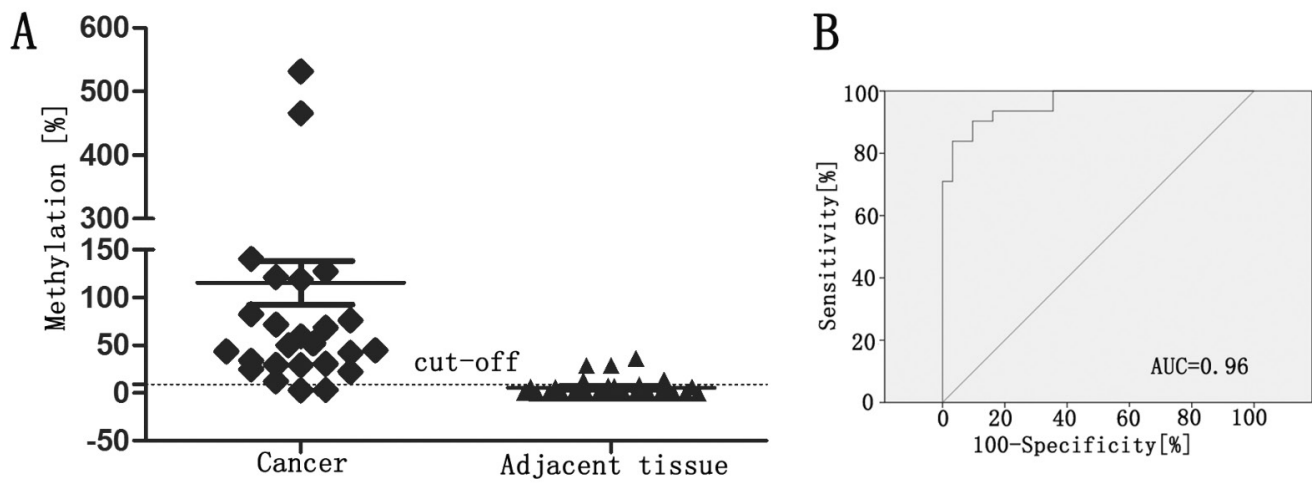

Suppl. Figure S1. Combined SHOX2 and PTGER4 DNA methylation expression in lung tissues. DNA was isolated from 31 matched patients' FFPE samples (cancer and adjacent tissue) and subjected to methylation specific PCR analysis. A) The higher methylation level of SHOX2 and PTGER4 measured in tumor and adjacent samples when using optimal cut-off $8.9 \%$ for sample analysis. B) ROC and the resulting AUC analysis of combined SHOX2 and PTGER4 study (AUC=0.96). 